\title{
Pembangunan Sistem Informasi Tracer Study Alumni Pada Program Studi Informatika Universitas Jenderal Achmad Yani
}

\author{
Rizky Bayu Oktavian ', Tachbir Hendro, P2, Asep Id Hadiana ${ }^{3}$ \\ ${ }_{, 1}^{\prime}$ Rizky Bayu Oktavian,Jln Jenderal H Amir Machmud No 47, Cimahi 40526, Indonesia \\ e-mail: rizkybayuoktavian@gmail.com ${ }^{1}$
}

\begin{tabular}{l}
\hline INFORMASI ARTIKEL \\
\hline Sejarah Artikel: \\
Diterima Redaksi : 19 April 2020 \\
Revisi Akhir : 04 Juli 2020 \\
Diterbitkan Online : 04 Juli 2020 \\
\hline
\end{tabular}

Kata Kunci :

Tracer Study, Customer Relationship

Management, Sistem Informasi

\section{Korespondensi :}

Telepon / Hp : +62 85377922751

E-mail : rizkybayuoktavian@gmail.com

\begin{abstract}
A B S T R A K
Tracer Study adalah suatu mekanisme yang dilakukan oleh berbagai pihak untuk melacak alumni dalam rangka untuk mengukur relevansi tujuan dan proses pendidikan dengan kondisi alumni saat ini. Tracer Study dilakukan antara 1-3 tahun setelah lulus dan bertujuan untuk mengetahui outcome pendidikan dalam bentuk transisi dari dunia pendidikan tinggi ke dunia kerja. Customer Relationship Management ( CRM ) adalah strategi bisnis dengan menerapkan teknologi informasi pada perusahaan secara komprehensif, handal, dan terintegrasi. dengan begitu semua proses dan interaksi saling membantu mempertahankan dan mengembangkan hubungan yang bermanfaat. BAN - PT merupakan satu-satunya badan akreditasi yang memperoleh wewenang dari Kementerian Riset, Teknologi dan Pendidikan Tinggi Republik Indonesia dalam meningkatkan mutu pendidikan tinggi. Kegiatan penelusuran alumni juga merupakan pemenuhan standar yang telah dipersyaratkan oleh Badan Akreditasi Nasional Perguruan Tinggi (BAN PT). Kurangnya umpan balik ( feedback ) dari alumni dengan jurusan mengakibatkan jurusan kesulitan untuk melakukan pelacakan terhadap alumni yang sudah lulus dan juga mempertahankan alumni untuk selalu mengupdate informasi mereka merupakan suatu hal yang sulit untuk dilakukan, padahal alumni merupakan produk keluaran dari suatu institusi pendidikan, yang mana kualitas alumni menunjukan kualitas dari institusi pendidikan tersebut. Serta tidak adanya suatu wadah yang dapat membantu mahasiswa aktif dalam mendapatkan informasi tentang dunia kerja bidang informatika. Tujuan yang ingin dicapai dari penelitian ini adalah membangun sebuah perangkat lunak sistem informasi tracer study di Universitas Jenderal Achmad Yani yang diharapkan dapat membantu jurusan dalam mengelola feedback dari alumni dan sebagai wadah untuk bertukar informasi antara alumni dengan sesama alumni maupun dengan mahasiswa aktif.
\end{abstract}

\section{PENDAHULUAN}

Tracer Study adalah suatu mekanisme yang dilakukan oleh berbagai pihak untuk melacak alumni dalam rangka untuk mengukur relevansi tujuan dan proses pendidikan dengan kondisi alumni saat ini [1] . Tracer Study dilakukan antara 1-3 tahun setelah lulus dan bertujuan untuk mengetahui outcome pendidikan dalam bentuk transisi dari dunia pendidikan tinggi ke dunia kerja [2]. Sedangkan yang dimaksud dengan alumni adalah produk dari suatu institusi pendidikan, kualitas alumni menunjukan kualitas dari institusi pendidikan tersebut, fakta tersebut semakin terasa khususnya untuk alumni dari perguruan tinggi [3]. Tingkat keberhasilan sebuah perguruan tinggi dalam menghasilkan lulusan dapat dilihat dari sejauh mana lulusannya berperan dan mengamalkan ilmu dalam bidangnya serta diterima oleh masyarakat [4].

Menurut kemendikbud, situasi tracer study di Indonesia saat ini dapat dikatakan masih berada dalam tahapan awal [5]. Bisa dikatakan penerapan tracer study masih belum diimplementasikan pada setiap instansi karena menurut kemendikbud tracer study di Indonesia masih berada dalam tahapan awal. Pelacakan alumni perlu dilakukan agar setiap perguruan tinggi khususnya program studi dapat mengevaluasi seberapa besar lulusannya dapat terserap di dunia kerja sesuai dengan bidang ilmu yang ditekuninya di bangku kuliah [6].

Universitas Jenderal Achmad Yani yang biasa disingkat menjadi UNJANI merupakan hasil pengembangan dari sekolah - sekolah tinggi yang dikelola oleh Yayasan Kartika Eka Paksi ( YKEP ) [7].

BAN - PT merupakan satu-satunya badan akreditasi yang memperoleh wewenang dari Kementerian Riset, Teknologi dan Pendidikan Tinggi Republik Indonesia dalam meningkatkan mutu pendidikan tinggi [8]. Kegiatan penelusuran alumni juga merupakan pemenuhan standar yang telah dipersyaratkan oleh Badan Akreditasi Nasional Perguruan Tinggi (BAN PT) [9].

Saat ini pada Universitas Jenderal Achmad Yani tepatnya pada fakultas sains dan informatika penggunaan atau penerapan tracer study ini belum 
dilakukan, padahal tracer study sangat penting karena bisa digunakan untuk membantu mengukur relevansi tujuan dan proses pendidikan dengan kondisi alumni saat ini, kurangnya umpan balik antara alumni dengan jurusan informatika saat ini mengakibatkan jurusan kesulitan untuk melakukan pelacakan terhadap alumni yang sudah lulus .

Tracer study juga bisa membantu pihak jurusan dalam memenuhi syarat akreditasi yang dipersyaratkan oleh BAN-PT. Selain itu untuk menghadapi persaingan dunia kerja saat ini, pihak perguruan tinggi perlu merancang sistem pendidikan yang sesuai dengan perubahan tuntutan lingkungan eksternal [10] dimana untuk mengetahui perubahan tuntutan lingkungan eksternal tersebut didapatkan salah satunya adalah lewat pengalaman alumni yang sudah terjun langsung ke dalam dunia kerja, dan banyaknya data alumni yang belum dikelola secara optimal oleh pihak jurusan mengakibatkan data tersebut belum dimanfaatkan secara maksimal untuk berbagai kepentingan. Selain itu permasalahan yang timbul setelah data alumni didapatkan ialah memastikan bahwa alumni tersebut selalu mengupdate informasi mengenai dirinya dalam kurun waktu tertentu.

Maka oleh sebab itu diperlukanlah sebuah sistem informasi tracer study yang menggunakan konsep CRM untuk memastikan bahwa alumni tersebut selalu mengupdate informasi mengenai dirinya serta dapat mengelola feedback dari alumni yang nantinya feedback tersebut dapat dimanfaatkan untuk berbagai keperluan baik untuk keperluan jurusan ataupun wadah mahasiswa aktif mencari informasi untuk keperluan akademisnya.

Tujuan yang ingin dicapai dari penelitian ini adalah membangun sebuah perangkat lunak sistem informasi tracer study pada program studi informatika Universitas Jenderal Achmad Yani yang dapat membantu memberikan rekomendasi lowongan pekerjaan pada fresh graduate, membantu jurusan informatika dalam mengelola data alumni dan menjadi wadah pertukuran informasi antara alumni dengan sesama alumni ataupun alumni dengan mahasiswa aktif.

\section{METODE PENELITIAN}

Metode penelitian ini menggunakan metode pengembangan perangkat lunak model waterfall yang mana pada bagian terakhir yaitu bagian pemeliharaan dihilangkan agar nantinya penelitian ini selesai dan jika tidak dihilangkan bagian tersebut maka penelitian ini tidak akan selesai - selesai. model pengembangan ini bersifat linear dari tahap awal pengembangan system yaitu tahap perencanaan sampai tahap akhir pengembangan system yaitu tahap pemeliharaan. Tahapan berikutnya tidak akan dilaksanakan sebelum tahapan sebelumnya selesai dilaksanakan dan tidak bisa kembali atau mengulang ke tahap sebelumnya[11]. Contoh model waterfall yang telah dihilangkan bagian pemeliharaannya bisa dilihat pada gambar 1 .

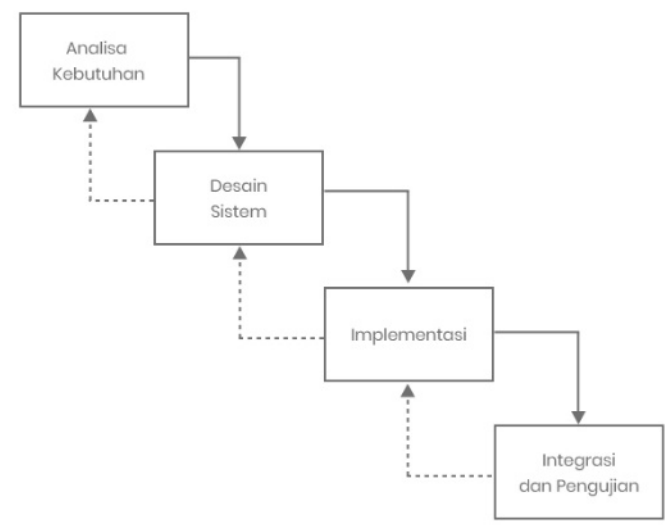

Gambar 1 Metode Waterfall

Metode pengumpulan data yang dilakukan pada penelitian ini diambil melalui beberapa cara yaitu :

a. Studi Pustaka

Pada tahap ini dilakukan studi pustaka untuk mendapatkan informasi pendukung yang berkaitan dengan penelitian.

b. Observasi

Pada tahap ini dilakukan pengamatan dan pencatatan terkait apa saja yang dibutuhkan sistem serta proses bisnisnya untuk sistem tracer study pada Universitas Jenderal Achmad Yani.

c. Wawancara

Pada tahap ini melakukan proses penyampaian sejumlah pertanyaan secara tatap muka kepada pihak yang terkait di Universitas Jenderal Achmad Yani untuk mendapatkan informasi mengenai komponen-komponen yang dibutuhkan.

\section{PERANCANGAN SISTEM}

Proses pengembangan sistem yang dilakukan dalam sistem informasi tracer study ini mengacu pada langkah sebelumnya pada metodologi penelitian. Dimana pada metodologi penelitian disebutkan dalam melakukan pengembangan sistem meliputi tahap analisa kebuthan, desain sistem, implementasi, integrasi dan pengujian.

\subsection{Tahap Analisa Kebutuhan}

Tahapan ini didapatkan dari hasil pengumpulan data yang dijelaskan pada langkah metode penelitian dimana setelah dianalisa menghasilkan sebuah kebutuhan sistem yaitu : mengelola alumni, menglola mahasiswa aktif, mengelola artikel, mengelola lowongan kerja, mengelola feedback, mengelola user, mengirim notifikasi, dan melihat laporan. Dimana nantinya setiap role memiliki hak akses yang berbeda beda dalam mengoperasikan sistem informasi ini, untuk lebih jelasnya lagi dapat dilihat pada use case pada gambar 2. 


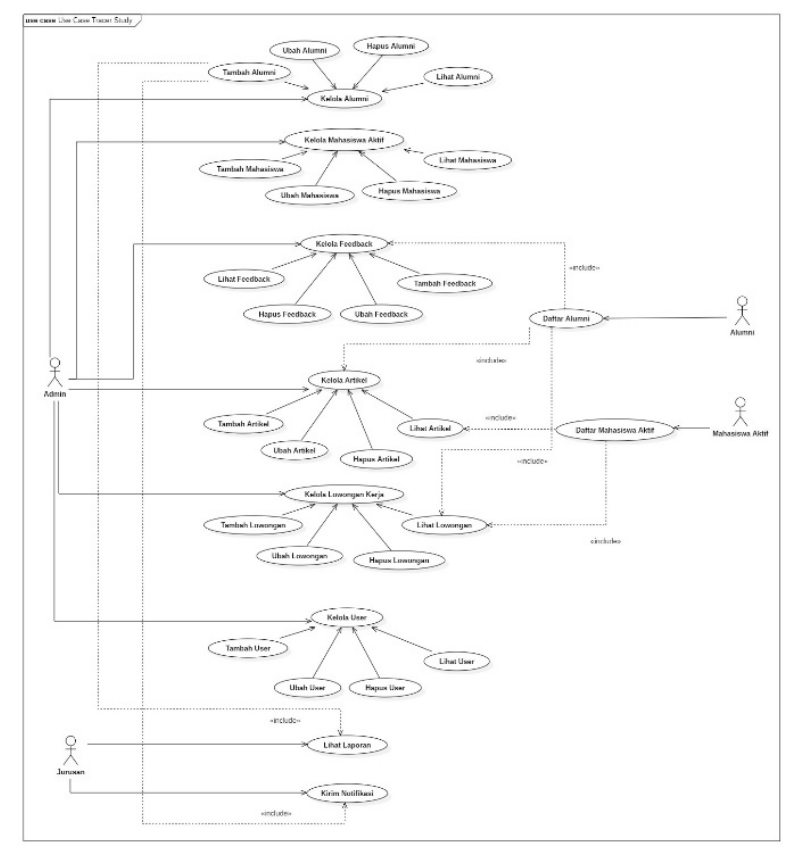

Gambar 2. Use Case Sistem

\subsection{Desain Sistem}

Sistem yang dibangun nantinya dapat diakses melalui 3 platform yaitu web, android, ios, dimana untuk dapat melakukan cross platform tersebut diperlukanlah sebuah teknologi yang mampu mengintegrasikan data, dan dipilihlah teknologi REST API untuk menyelesaikan permasalahan tersebut, dimana untuk arsitektur sistem yang akan dibuat dapat dilihat pada gambar 2 .

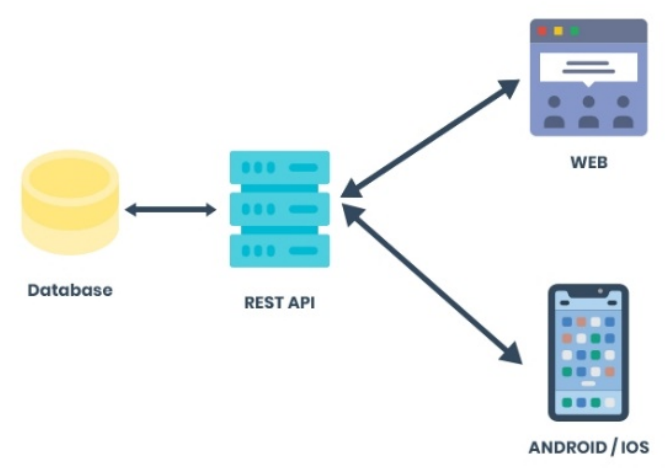

Gambar 3. Arsitektur Sistem

Dengan adanya REST API maka sistem tersebut dapat dikases cross platform tanpa khawatir datanya berbeda, karena menggunakan database yang sama, dan untuk keaman datanya sendiri di dalam sistem ini membuat sebuah authentication sehingga tidak bisa diakses oleh sembarang orang API nya walaupun orang tersebut sudah mengetahui link dari API, karena harus menggunakan authentication terlebih dahulu sebelum dapat mengakses data tersebut.

\subsection{Implementasi}

Tahap implementasi adalah tahap untuk mengubah rancangan desain ke dalam sebuah sistem yang nyata yang nantinya akan digunakan. Dimana dalam mengimplementasikannya pada penelitian ini menggunakan framework Code Igniter untuk membuat tampilan website dan REST API, database MySql, dan untuk aplikasi mobile menggunakan React Native.

a. Perancangan Halaman Dashboard Admin

Halaman dashboard admin ini adalah halaman yang hanya dapat diakses oleh admin saja dimana hak akses admin dalam sistem ini adalah mengelola alumni, mengelola mahasiswa aktif, mengelola artikel, mengelola lowongan kerja, mengelola feedback, dan mengelola user.

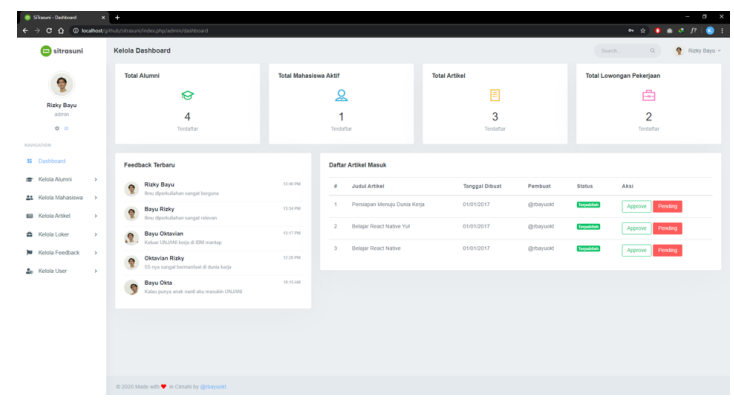

Gambar 4. Halaman Dashboard Admin

b. Perancangan Halaman Dashboard Jurusan

Halaman dashboard jurusan ini adalah halaman yang hanya dapat diakses oleh jurusan saja dimana hak akses jurusan dalam sistem ini adalah melihat laporan dan mengirim notifikasi kepada pengguna.

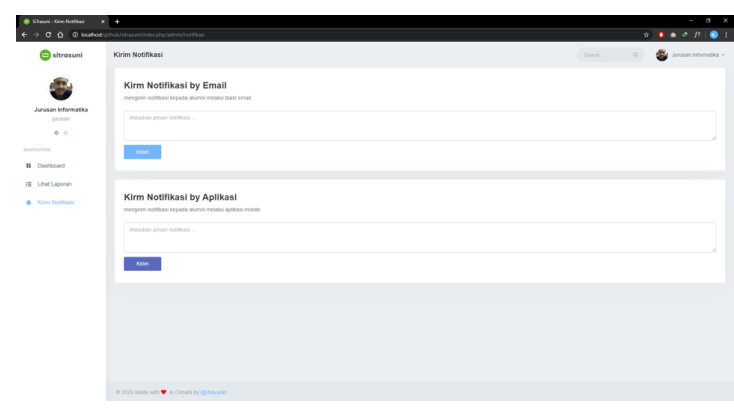

Gambar 5. Halaman Dashboard Alumni

c. Perancangan Halaman Dashboard Alumni

Halaman dashboard alumni ini adalah halaman yang hanya bisa diakses oleh alumni yang telah terdaftar pada sistem dan hak akses untuk alumni sendiri yaitu : merubah informasi data diri, mengelola artikel, mengelola lowongan kerja, mengelola feedback. 


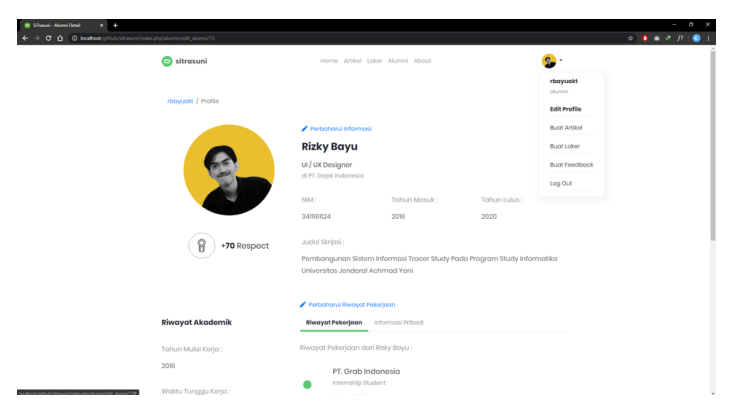

Gambar 6. Halaman Dashboard Alumni

d. Perancangan Dashboard Mahasiswa Aktif

Halaman dashboard mahsiswa aktif ini hanya dapat diakses oleh mahasiswa aktif yang telah terdaftar pada sistem yang mana memiliki hak akses untuk mengubah profile dan membuat feedback.

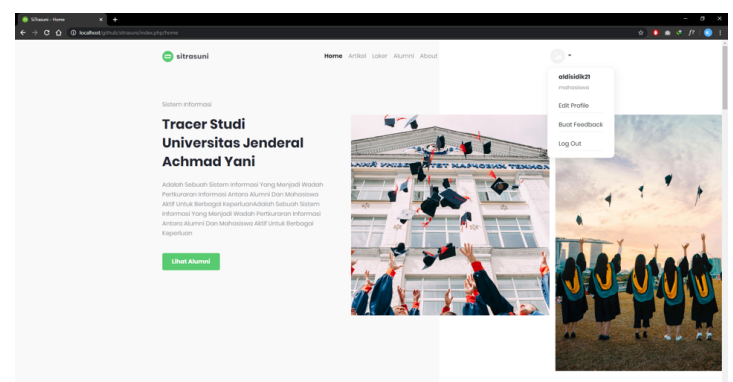

Gambar 7. Halaman Dashboard Mahasiswa

e. Perancangan Halaman List Artikel

Halaman list artikel ini berisikan list artikel yang telah dibuat oleh admin maupun alumni yang mana nantinya semuanya dimunculkanpada halaman ini.

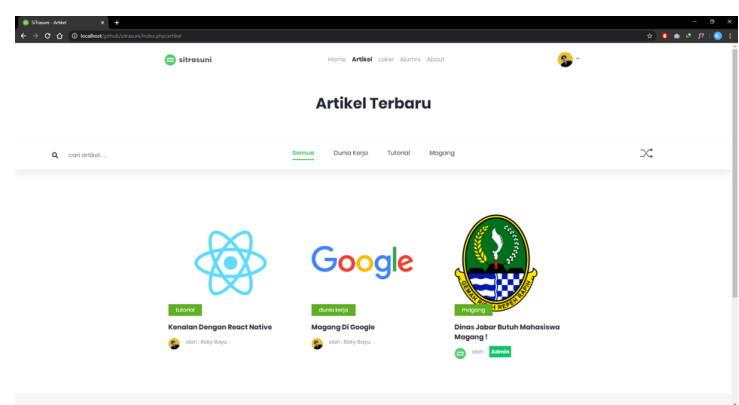

Gambar 8. Halaman List Artikel

f. Perancangan Halaman List Lowongan Kerja

Halaman list lowongan kerja ini berisikan list lowongan kerja yang telah dibuat oleh admin maupun oleh alumni, fungsinya adalah sebagai sarana pertukaran informasi tentang dunia kerja.

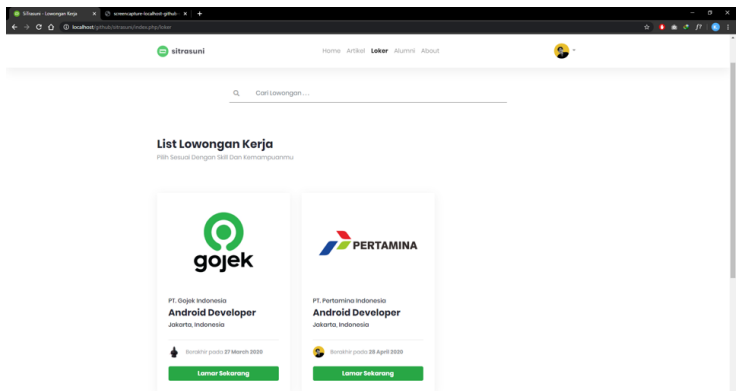

Gambar 9. Halaman List Lowongan

g. Perancangan Halaman List Alumni

Halaman list alumni ini adalah halaman untuk melihat alumni dari jurusan informatika dimana didalamnya terdapat informasi mengenai alumni tersebut, atau dengan kata lain kita dapat melakukan trace terhadap alumni pada halaman ini.

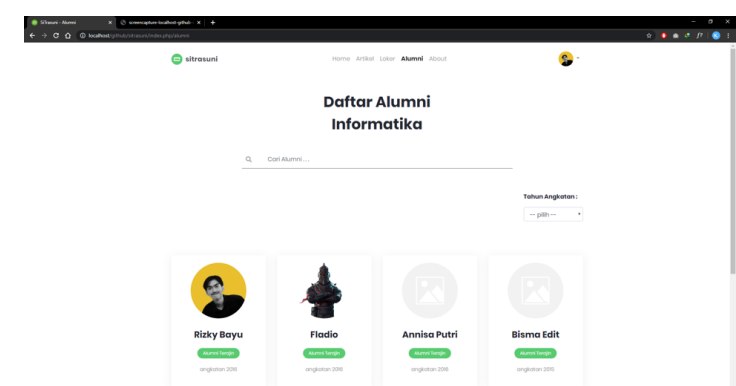

Gambar 10. Halaman List Alumni

h. Perancangan Halaman Aplikasi Mobile Home dan List Artikel

Aplikasi mobile pada gambar 11 merupakan tampilan dari aplikasi yang dibuka dari android, dimana terdapat halaman home yang berisikan informasi mengenai artikel, lowongan kerja, alumni. Lalu ada halaman artikel dimana isinya adalah list artikel yang telah dibuat oleh admin maupun alumni.

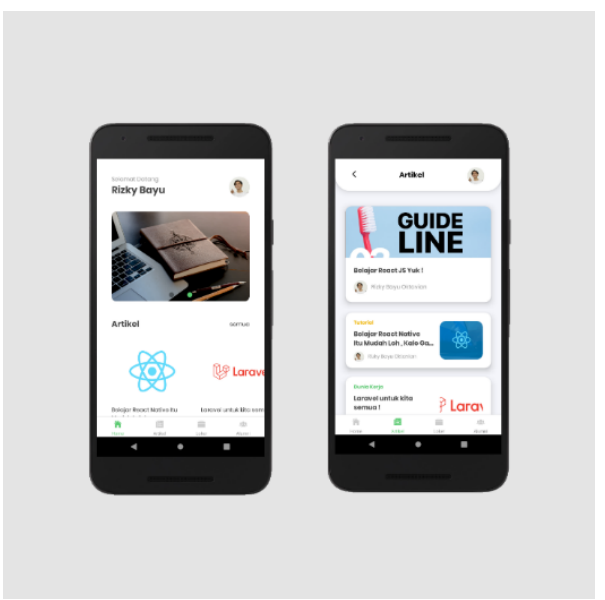

Gambar 11. Halaman Dashboard \& List Artikel 
i. Perancangan Halaman Aplikasi Mobile List Lowongan Kerja dan List Alumni

Halaman ini berisikan informasi mengenai lowongan kerja dan data alumni, dimana dalam pengambilan datanya berasal dari REST API yang telah dibuat sehingga datanya saling terintegrasi satu dengan lainnya.

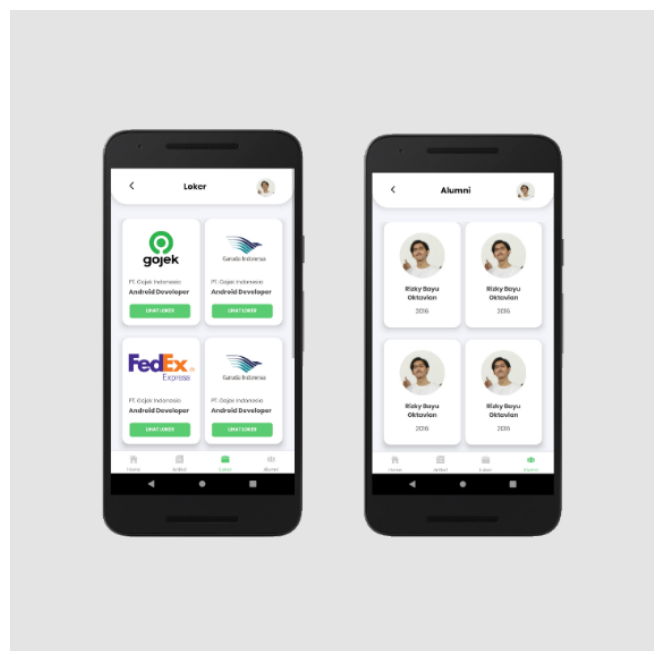

Gambar 12. Halaman List Lowongan dan List Alumni

\section{KESIMPULAN}

Berdasarkan hasil analisa dan pengembangan sistem informasi tracer studi program studi Universitas Jenderal Achmad Yani ini dapat diambil beberapa kesimpulan adalah sebagai berikut :

a. Sistem informasi ini mampu menangani pengelolaan data alumni, mahasiswa aktif, artikel, lowongan kerja, feedback, dan user.

b. Sistem informasi ini dapat diakses melalui website dan aplikasi mobile ( android \& ios ) yang mana data yang digunakan berasal dari database yang sama dan menggunakan teknologi REST API.

c. Sistem informasi ini dapat membantu jurusan dalam melakukan pelacakan terhadap alumni yang telah lulus.

d. Sistem informasi ini dapat membantu jurusan dalam memenuhi persyaratan akreditasi.

e. Sistem informasi ini dapat mengingatkan alumni untuk selalu memperbaharui informasi pribadinya melalui fitur email blast dan push notification yang akan mengirim notifikasi langsung kepada aplikasi mobile.

Dengan adanya sistem infromasi tracer study ini maka jurusan dapat dengan mudah melalukan pelacakan terhadap alumni yang telah lulus, dapat mempermudah jurusan dalam memenuhi persyaratan akreditasi dan tentunya sistem informasi ini dapat digunakan sebagai wadah pertukaran informasi antara alumni dan mahasiswa aktif baik itu untuk pertukaran informasi dunia kerja maupun informasi untuk melakukan magang maupun tempat penelitian untuk mahasiswa aktif, sehingga permasalahan yang telah diidentifikasi itu dapat terselesaikan dengan sistem informasi tracer study informatika ini yang diberi nama siTrasuni ( Sistem Informasi Tracer Study informatika UNJANI ).

\section{DAFTAR PUSTAKA}

[1] S. Alfie Nur Rahmi, Kusrini, "Pengembangan Sistem Informasi Tracer Study Online Berbasis Website Di Stmik Amikom Yogyakarta," Vol. 6, No. 2, Pp. 108-117, 2014.

[2] L. Hakim Et Al., "Perancangan Sistem Tracer Alumni Pada Stmik Musi Rawas Berbasis Web Mobile," Vol. 2, No. 2, Pp. 108-116, 2017.

[3] M. Saleh And N. Safriadi, "Tracer Study Alumni Fakultas Teknik Universitas Tanjungpura Dengan Sistem Informasi Berbasis Web," Vol. 4, No. 1, Pp. 38-44, 2012.

[4] L. L. S. Evi Roviati, Amrina Rosyada , Deden Jalaludin, Ela Fitria , Elan Jaelani, "Tracer Study: Studi Rekam Jejak Alumni Dan Respons Stakeholder Jurusan Tadris Ipa-Biologi," Vol. 5, 2015.

[5] S. M. P, Y. H. Yadi, And W. Susihono, "Evaluasi Tracer Study Untuk Pembelajaran Dengan Pendekatan Ergonomi Makro," Vol. 1, No. 4, Pp. 284-288, 2013.

[6] P. Studi, F. I. Pendidikan, And U. N. Makassar, "Tracer Study Alumni : Upaya Pengembangan Prodi Bimbingan Konseling Universitas Negeri Makassar," Vol. 2, Pp. 32-40, 2017.

[7] Unjani, "Sambutan Rektor," 2016. [Online]. Available: $\quad$ http://www.unjani.ac.id/statis-2sambutan-rektor.html. [Accessed: 16-Oct-2019].

[8] Ristekdikti, "Ban-Pt." [Online]. Available: https://kelembagaan.ristekdikti.go.id/index.php/tag/ ban-pt/. [Accessed: 16-Oct-2019].

[9] J. Arifin And J. Arifin, "Tracer Study Alumni Jurusan Perbankan Syariah Fakultas Ekonomi Dan Bisnis Islam Iain Walisongo Semarang," Vol. Vi, Pp. 91-130.

[10] L. Suharti And F. P. Laksono, "Studi Penelusuran ( Tracer Study ) Terhadap Alumni Program Studi Manajemen," Pp. 231-248.

[11] A. D. A. Rani Santoso, "Perbandingan Model Waterfall Dan Prototyping Untuk Pengembangan Sistem Informasi," Ther. Ggw., vol. 111, no. 5, pp. 756-757 passim, 1972. 